\title{
LOS PRIMEROS AYUNTAMIENTOS LIBERALES \\ EN PUERTO RICO (1812-1814 Y 1820-1823)
}

\section{INTRODUCCIÓN}

Antes de hablar de los ayuntamientos surgidos de las Cortes de Cádiz, parece obligado considerar, al menos de manera muy somera, dos cuestiones fundamentales en relación con el tema que nos atañe: el desarrollo de los municipios puertorriqueños hasta 1812; y la situación política de la isla en los momentos inmediat os a la entrada en vigor del texto constitucional gaditano.

Es algo confirmado por la Historiografía que la forma en que se establecieron los municipios en América tiene su génesis en la tradición medieval castellana que concedió a los concejos de sus villas y ciudades amplias autonomías para gobernarse.

Con el fortalecimiento de la monarquía autoritaria, la vida política de los municipios castellanos fue languideciendo, de tal manera que cuando se comienza la conquista de América los concejos castellanos, al menos los de las ciudades y villas importantes, no son ya entes autonómicos como lo fueron en el bajomedievo.

Es evidente; que los conquistadores llevaron al continente descubierto, las mismas formas de gobierno para los recientes municipios creados, que Castilla mantenía en su reino en aquella fecha.

1 Alemparte, Julio: El Cabildo en Chile Colonial. Santiago, 1940, pág. 37.-Avellá, Joaquín: Los Cabildos Coloniales. Madrid, 1934, pág. 33.-Bayle, S. J., Cons tantino: Los Cabildos Seculares en la América Española. Madrid, 1952, pág. 17.-. Bayle, S. J., Constantino: Los Municipios y los Indios. *Missionalia Hispánica». Año VII, núm. ¿1. Madrid, págs. 409-442.--Domínguez Company, Francisco: La vida en las pequentas ciudades hispanoamericanas de la conquista. Madrid, 1978, péginas 26-36.-Ots Capdequí, José M.a: El Municipio Hispanoamericano. Anuario de Historia del Derecho Español». Madrid, 1924, tomo I, págs. 94-157. 
No obstante, el paralelismo existente entre los municipios indianos y los de Castilla en los primeros momentos de la colonización, fue desapareciendo a lo largo del tiempo. Una legislación específica dada expresamente para los concejos de Indias, alejó a éstos de la evolución que siguieron los municipios de la metrópoli. Aunque las modificaciones operadas fueron distintas, sin embargo, al llegar el siglo XIX, tanto unos como otros habían perdido sus autonomías de gobierno. ${ }^{2}$

Ciñéndonos a los municipios puertorriqueños, diremos que casi durante todo el siglo XVIII, sólo existieron en la isla dos: el de la capital, y el de la villa de San Germán. ${ }^{3}$ El gobierno de Carlos III introdujo en los municipios españoles, y por supuesto en los de Puerto Rico, un cierto halo de vigor. A pesar de ello se consiguió muy poco en lo que se refiere a revivir la importancia política y social del funcionamiento de éstos. La propiedad de los cargos municipales, la escasez de medios de los habitantes de la isla, las limitaciones en materia de impuestos, la supeditación en materia legislativa a la Audiencia de Santo Domingo y en última instancia al Consejo de Indias, redujeron a los cabildos puertorriqueños a lo largo de los siglos, a una casi absoluta nulidad. ${ }^{4}$

La segunda cuestión que nos planteábamos al comienzo, era la situación política de Puerto Rico en los momentos en que fue proclamada la Constitución de 1812.

En efecto, los últimos años del siglo XVIII y primeros del XIX fueron ricos en acontecimientos para las colonias españolas en América. La revolución de Haití, los sucesos de Bayona, y las ideas emanadas de la Revolución Francesa, parece que hicieron germinar en Puerto Rico un sentimiento desconocido hasta entonces, que si

2 Tomás Valiente. Francisco: Gobierno e Instituciones en la Espana del Antiouo Réoimen. Madrid, 1982, pág. 273.

3 Caro Costas, Aída R.: Legislación Municipal Puertorriquena del siglo XVIII. San Juan de Puerto Rico, 1971, pág. 9.

4 C. H. Haring: Las Instituciones Coloniales de Hispanoamérica. (Siglos XVI a XVIII). Instituto de Cultura Puertorriqueña. San Juan de Puerto Rico, 1957, pág. 16. 
no podía tildársele de separatista, por lo menos tenía un cicrto matiz protonacionalista. ${ }^{5}$

No obstante, mientras que las conspiraciones de 1810 y 1811 en Cuba, son movimientos claramente nacionalistas, las aspiraciones de los puertorriqueños más radicales sólo se traducen en la colocación de algún pasquín, la actitud más o menos atrevida del Ayuntamiento de San Germán respecto a la independencia de la isla -en caso de extinguirse la dinastía borbónica en España-, la solicitud de los ayuntamientos de que los cargos públicos fuesen ocupados preferentemente por puertorriqueños, etc. ${ }^{6}$

En las circunstancias señaladas, la Constitución de Cádiz fue proclamada en Puerto Rico, el 14 de julio de 1812, en medio de una calma casi completa.

Es bien conocido que uno de los objetivos más inmediatos pretendido por las Cortes gaditanas, fue la formación de nuevos ayuntamientos. El artículo 310 - Título VI del texto constitucional- lo pone de manifiesto: «Se pondrán ayuntamientos en los pueblos que no le tengan, y en que convenga le haya, no pudiento dejar de haberle en los que por sí o con su comarca lleguen a mil almas, y también se les señalará término correspondiente». ${ }^{7}$ Estc aspecto de la Constitución se reflejó rápidamente en Puerto Rico, quedando la isla convertida en una sola provincia, con su correspondiente Diputación Provincial.

En las páginas que siguen hablaremos de la constitución de los ayuntamientos cuasi populares correspondientes a los dos breves períodos liberales del primer cuarto del siglo XIX, asimismo abordaremos el funcionamiento de éstos y su relación con la Diputación Provincial, el gobierno superior de la isla, y las Cortes de la Nación Española. pág. 21.

5 Figueroa, L.: Breve Historia de Puerto Rico, Río Piedras, 1970, tomo II.

6 Ibidem, pag. 27.

7 Garófano, R. y Páramo, J. R. de: La Constitución Gaditana de 1812. Cádiz, 1883, páç. 84. 
LOS AYUNTAMIENTOS PUERTORRIQUEÑOS

DURANTE EL BIENIO CONSTITUCIONAL

Como bien es sabido la Constitución de 1812, en su Título VI, Capítulo I, artículos del 309 al 323, se refiere a la formación de los ayuntamientos en los pueblos de la provincia, al número de individuos que han de componer éstos, y a las atribuciones que tendrán en materia económica, judicial, legislativa, sanitaria y de instrucción pública. Un real decreto de 23 de mayo de 1812, dado en Cádiz, y otro aclaratorio del 10 de julio del mismo año, señalan y especifican las directrices a seguir para la formación de los municipios constitucionales.

El primero de ellos llegó a poder del gobernador y capitán general de la isla, don Salvador Meléndez Bruna, el 21 de agosto de dicho año. Su articulado regula minuciosamente los requisitos para la creación de nuevos ayuntamientos, así como el modo en que se había de efectuar la clección de los miembros de las corporaciones.

El segundo, fue recibido en Puerto Rico la noche del 3 de septiembre de 1812. Es un documento aclaratorio del anterior, concretamente en lo tocante al artículo 3." de aquél. En él se indica el cese de las funciones de los regidores perpetuos y de todos los individuos que en 1812 componían los cabildos existentes en la isla. Eso sí, con derecho a ser elegidos en la próxima elección de los nuevos cargos concejiles. ${ }^{8}$

Ya con anterioridad, se había formado en Puerto Rico una Junta Preparatoria cuya misión principal era revisar el censo de población, y fijar el número de electores que correspondería a cada partido para elegir el diputado a Cortes. El 11 de agosto de 1812, la Junta reunida en la Real Fortaleza presentó al gobernador Meléndez el censo que él había mandado elaborar y que reproducimos a continuación. De ningún modo se contabilizaba a todos los

8 Archivo General de Indias (en adelante A.G.I.), Ultramar, 426. Real decreto de 10 de julio de 1812 . 
habitantes de la isla, sino únicamente a los que la Constitución contemplaba como ciudadanos. ${ }^{9}$

Cuadro n. ${ }^{\circ} 1$

HABITANTES BLANCOS

$\begin{array}{lccrr}\text { Parroquias } & \begin{array}{c}\text { Padres } \\ \text { de familias }\end{array} & \begin{array}{c}\text { Madres } \\ \text { de familias }\end{array} & \text { Hijos } & \text { Hijas } \\ \text { C. de P. Rico } & 907 & 751 & 820 & 884 \\ \text { Guaynabo } & 98 & 100 & 214 & 130 \\ \text { Bayamón } & 560 & 770 & 469 & 430 \\ \text { Toa Alta } & 273 & 301 & 411 & 417 \\ \text { Toa Baja } & 85 & 95 & 318 & 264 \\ \text { Vega Alta } & 45 & 43 & 117 & 103 \\ \text { Corozal } & 85 & 87 & 247 & 224 \\ \text { Vega Baja } & 150 & 148 & 350 & 355 \\ \text { Manatí } & 775 & 822 & 1.740 & 1.724 \\ \text { Arecibo } & 485 & 562 & 1.194 & 1.331 \\ \text { Camuy } & 44 & 4.2 & 68 & 78 \\ \text { Utuado } & 305 & 359 & 777 & 815 \\ \text { Tuna } & 405 & 448 & 1.076 & 1.100 \\ \text { Pepino } & 518 & 536 & 1.241 & 1.162 \\ \text { Moca } & 449 & 464 & 389 & 988 \\ \text { Aguadilla } & 716 & 799 & 1.595 & 1.534 \\ \text { Aguada } & 662 & 691 & 1.430 & 1.252 \\ \text { Rincón } & 520 & 489 & 868 & 965 \\ \text { Añasco } & 645 & 471 & 1.191 & 1.119 \\ \text { Mayagüez } & 685 & 730 & 1.260 & 1.200 \\ \text { Cabo Rojo } & 329 & 318 & 761 & 730 \\ \text { San Germán } & 551 & 590 & 11.66 & 1.168 \\ \text { Yauco } & 276 & 305 & 659 & 606 \\ \text { Peñuelas } & 185 & 190 & 442 & 460\end{array}$

9 Garófuno, R. y Páramo, J. R.: La Constitución..., páq. 7. 


$\begin{array}{lrrrr}\text { Parroquias } & \begin{array}{c}\text { Padres } \\ \text { de familias }\end{array} & \begin{array}{c}\text { Madres } \\ \text { de familias }\end{array} & \text { Hijos } & \text { Hijas } \\ \text { Ponce } & 718 & 404 & 1.124 & 901 \\ \text { Juana Díaz } & 129 & 123 & 225 & 194 \\ \text { Coamo } & 210 & 270 & 268 & 259 \\ \text { Guayama } & 66 & 80 & 264 & 288 \\ \text { Patillas } & 112 & 124 & 250 & 103 \\ \text { Barranquitas } & 140 & 160 & 200 & 210 \\ \text { Cidra } & 84 & 82 & 178 & 167 \\ \text { Cayey } & 88 & 105 & 222 & 203 \\ \text { Hato Grande } & 104 & 100 & 225 & 223 \\ \text { Caguas } & 400 & 409 & 1.250 & 1.340 \\ \text { Juncos } & 133 & 159 & 202 & 297 \\ \text { Piedras } & 55 & 47 & 150 & 114 \\ \text { Maunabo } & 66 & 68 & 111 & 82 \\ \text { Yabucoa } & 174 & 179 & 374 & 301 \\ \text { Humacao } & 352 & 298 & 535 & 612 \\ \text { Naguabo } & 216 & 129 & 261 & 257 \\ \text { Fajardo } & 352 & 370 & 832 & 731 \\ \text { Luquillo } & 48 & 42 & 78 & 107 \\ \text { Loiza } & 92 & 88 & 156 & 138 \\ \text { Trujillo } & 83 & 80 & 182 & 149 \\ \text { Rio Piedras } & 69 & 72 & 134 & 139 \\ \text { Cangrejos } & 13 & 14 & 26 & 10 \\ & & & & \\ & 13.447 & 13.514 & 26.711 & 25.900\end{array}$

Resumen:

13.447 padres de familias.

13.514 madres de familias.

26.711 hijos.

25.990 hijas.

Total 79.662 habitantes de raza blanca. ${ }^{10}$

10 «stado que manifiesta el número de habitantes de la isla de Puerto Rico, de la clase que en él se expresa, deducida del censo general de su población en azosto de 1812x. (A.G.I., Ultramar, 430, cuaderno núm. 4). 
La otra labor importante que desarrolló la Junta Preparatoria fue la de dividir la isla en partidos para llevar a cabo la elección del diputado a Cortes, único representante que correspondía a Puerto Rico, según la Constitución gaditana. A tal efecto, la comisión encargada de ello, redactó un informe que proponía la división de la isla en cinco partidos. La Junta lo aprobó en bloque sin ninguna objeción, el 21 de agosto de 1812. La distribución de parroquias por partidos se hacía de la manera siguiente:

El de San Juan, el primero, lo formarían las parroquias de San Juan, Vega Alta, Toa Baja, Corozal, Vega Baja, Toa Alta, Bayamón, Río Piedras, Cangrejos, Guaynabo, Trujillo, Loiza, Luquillo, Fajardo, Naguabo, Humacao, Maunabo, Piedras, Barranquitas, Juncos, Caguas y Hato Grande.

El partido de la villa de San Germán, el segundo, estaría compuesto por las parroquias de San Germán, Mayagüez, Añasco, Cabo Rojo y Yauco.

El tercero sería el partido de Coamo, y los formarían las parroquias de Coamo, Juana Díaz, Ponce, Cayey, Cidra, Guayama, Patillas, Peñuelas y Yabucoa.

Aguada constituiría el cuarto partido, en cuyo término habían de quedar incluidas las parroquias de Aguada, Aguadilla, Rincón, Pepino y Moca.

Por último, Arecibo constituiría el quinto partido y le corresponderían: Arecibo, Manatí, Camuy, Utuado y Tuna. ${ }^{11}$

\section{Formación de los ayuntamientos constitucionales}

Una vez finalizada la misión de la Junta, el 13 de septiembre los habitantes de San Juan con derecho a voto se reunieron con objeto de nombrar a los compromisarios que habrían de elegir el ayuntamiento de la ciudad. La convocatoria había sido hecha previamente por el gobernador.

11 González Vales, Luis E.: La Primera Diputación Provincial. (1813-1814). «Revista del Colegio de Abogados de Puerto Rico», vol. 37, mayo 1976, pág. 244. 
Nombrados los 17 electores que correspondían a San Juan, el día 20 del mismo mes se votó el nuevo cabildo, que tomaría posesión dos días después. El mismo procedimiento se siguió en los demás pueblos de la isla, quedando formados los 40 nuevos ayuntamientos y reelegidos los cinco que ya existían, en las semanas siguientes. ${ }^{12}$

De este modo, para primeros de noviembre de 1812 , en Puerto Rico se habían constituido ya casi todos los ayuntamientos del bienio liberal. Sólo quedaban por constituirse el de Humacao y el de Rincón, pueblos correspondientes a los partidos de San Juan y Aguada respectivamente. Algunos pueblos, por carecer del número de vecinos suficiente, habían formado ayuntamientos con otros, como disponía el real decreto de 23 de mayo de $1812 .^{13}$ Así formarían un solo ayuntamiento los pueblos de Río Piedras y Cangrejos del partido de San Juan, del mismo modo que San Germán tendría agregado a su ayuntamiento el pueblecito de Sabana Grande. Si la creación de los nuevos municipios supuso un aliciente político para los habitantes de la isla, al menos en lo que se refiere a la participación para elegir los cargos concejiles, no debemos olvidar que la condición de ciudadano alcanzó solamente a una minoría, y por tanto la participación en las elecciones resultó ser muy escasa en comparación con el número total de personas que poblaban el territorio puertorriqueño en aquella fecha. De las 182.989 almas que habitaban la isla en 1812, tan sólo $12.424 \mathrm{llc}$ gaban al rango de ciudadanos.

12 En Puerto Rico existieron únicamente dos cabildos hasta el siglo XIX: el de la capital, y el de la villa de San Germán. Sin embargo, la real cédula de 14 de enero de 1778, concedió el título de villas a las localidades de Aguada. Arecibo y Coamo. A cada una de éstas le asignaba un término municipal, que incluía un determinado número de pueblos. No obstante, el cumplimiento del citado mandato real fue retrasado por diversos motivos, entre ellos el mal estado urbanístico de las nuevas villas, y la falta de preparación de sus habitantes más cualiffcados para gobernar un municipio. (vid. Caro de Delgado, Aída R.: El Cabildo o Régimen Municipal Puertorriqueño en el Siglo XVIII. San Juan de Puerto Rico, 1965, tomo I, pár. 5).

En la junta electoral que en 1809 se formó para preparar las elecciones del primer diputado a Cortes, los representantes de los ayuntamientos de Aguada, Arecibo y Coamo, estuvieron presentes. Vid. Figueroa, L.: Breve Historia.... tomo II, pág. 27.

13 A.G.I., Ultramar, 426. Real decret॰ de 23 de mayo de 1812. 
En este sentido podemos decir que la distinción entre españoles y ciudadanos que idearon las Cortes de Cádiz, dejó sin derecho a voto en Puerto Rico, al igual que en el resto de la América española, a una gran mayoría de su población. ${ }^{14}$

\section{Nueva división de la isla en siete distritos electorales}

Es evidente que la división de la isla en cinco partidos se había hecho de manera circunstancial. Por eso, al quedar convertida en una provincia con su Diputación correspondiente, se procedió a realizar por parte de ésta una nueva distribución. La efectuada el año anterior entrañaba cierta desigualdad. La extensión superficial de los partidos resultaba ser muy desproporcionada, así como el número de pueblos que correspondía a cada uno.

La Diputación se reunió por primera vez el 5 de mayo de 1813, y el 14 del mismo se formó una comisión compuesta por los presbíteros don Antonio Sánchez y don Manuel Pizarro, con el fin de presentar un provecto en el que la nueva provincia española apareciese estructurada, desde el punto de vista administrativo, de manera distinta a como se había efectuado en los meses anteriores. El proyecto fue presentado a la Diputación Provincial, el 9 de junio del año en

14 En el artículo 5 de la Constitución de 1812, se establece que son españoles:

«1." Todos los hombres libres nacidos y avecindados en los dominios de las Españas, y los hijos de éstos.

2." Los extranjeros que hayan obtenido de las Cortes carta de naturaleea.

3. Los que sin ella lleven 10 años de vecindad, ganada según la ley, en cualquier pueblo de la monarquía.

4." Los libertos desde que adquieren la libertad en las Españas».

El derecho de ciudadania viene regulado por la Constitución doceañista en su Capítulo IV. Según el articulado de éste, ason ciudadanos aquellos españoles que por ambas líneas traen su origen de los dominios españoles de ambos hemisferios. y están avecindados en cualquier pueblo de los mismos dominios». (Art. 18). Asimismo -el artículo $19 \ldots$... establece que «es también ciudadano el extranjero que gozando ya de los derechos de español, obtuviere de las Cortes carta especial de ciudadano».

Los requisitos exigibles para obtener la carta de ciudadania, se especifican en los sucesivos artículos del citado Capitulo.

Por último, diremos que la Constitución de Cádiz, en su artículo 23 afirma tajantemente que «sólo los que sean ciudadanos podrán obtener empleos municipales. y elegir para ellos en los casos señalados por la ley». (Vid. Garófano, R. y Páramo, J. R. de: La Constitución..., págs. 4, 7, 8 y 9). 
cuestión, y resultó aprobado, una vez oído el dictamen de los comisionados.

La nueva división perseguía una igualación de los partidos, con un número proporcionado de pueblos y vecinos, para lo cual quedaría dividida la provincia en siete distritos, cuyas cabezas serían la capital, y los pueblos de Humacao, Guayama, Ponce, San Germán, Aguada y Arecibo.

Al partido o distrito de San Juan corresponderían 12 pueblos: Vega Alta, Vega Baja, Corozal, Toa Alta, Toa Baja, Bayamón, Guaynabo, Río Piedras, Cangrejos, Loiza, Trujillo y Caguas. El número total de vecinos que reunía era de 6.459 , incluyendo también los de San Juan.

Al de Humacao pertenecerían seis: Luquillo, Fajardo, Naguabo, Piedras, Yabucoa, y Juncos. Su número de vecinos: 2.541.

Al de Guayama cinco: Maunabo, Patillas, Hato Grande, Cidra y Cayey. En total sumaban 1.333 vecinos.

El de Ponce comprendería cuatro: Peñuelas, Barranquitas, Juana Díaz y Coamo. Su vecindad la componían 3.414 personas.

Al de San Germán, el segundo en importancia, correspondían cinco: Yauco, Sabana Grande, Cabo Rojo, Mayagüez, y Añasco. El número de vecinos era de 6.272.

Al de Aguada correspondían los pueblos de Aguadilla, Moca, Pepino y Rincón, con una vecindad de 3.158 personas.

Por último, al de Arecibo correspondían otros cuatro pueblos: Tuna, Utuado, Camuy y Manatí. Los vecinos que reunía eran 2.541.

Los comisionados, dejaron muy claro en su exposición que la división debía entenderse solamente por la conveniencia de que en el nombramiento de diputado a Cortes, resultaran siete lectores, en lugar de los cinco de aquel año. Asimismo, hicieron constar, que debido a la pobreza de la isla, a la situación que atravesaban sus pueblos, y también a que el número de vecinos radicados en las cabeceras de partidos no llegaba a 500, con las excepciones de San Juan y de San Germán, se debía suprimir en dichas cabezas de 
partido, al menos de momento, el juez letrado que establecía la Constitución. ${ }^{15}$

En la sesión de la Diputación Provincial celebrada el 6 de julio de 1813, se acordó que el número de jueces letrados que atenderían los asuntos judiciales de toda la isla sería solamente de dos: uno en la capital, y otro en San Germán. El de la capital, extendería su jurisdicción sobre 32 pueblos, y un total de 12.981 vecinos. El juez de San Germán tendría a su cargo 14 pueblos, con una cifra de 12.597 personas.

En los cuadros siguientes representamos los dos distritos más importantes de la isla, con juez letrado en sus respectivas cabezas de partido.

\author{
Cuadro n. ${ }^{\circ} 2$ \\ PARTIDO DE SAN GERMAN
}

San Germán

Juana Díaz

Ponce

Peñuelas

Yauco

Cabo Rojo

Mayagüez

Añasco

Rincón

Aguada

Aguadilla

Moca

Pepino

Tuna

Total
2.208 vecinos

318 ”

1.863 "

564 "

$815 »$

$613 "$

1.402 ”

1.234 "

565 ”

782 ”

812 ”

457 "

542 "

$422 ”$

12.597 vecinos

15 A.G.I., Ultramar, 430, cuaderno núm. 4. 
Cuadro n. ${ }^{\circ} 3$

PARTIDO DE LA CAPITAL

San Juan

1.582 vecinos

Coamo

Barranquitas

$442 》$

Cidra

227 »

Cayey

143 »

379 )

Guayama

308 )

Patillas

$112 》$

Hato Grande

229 "

Maunabo

162 »

Yabucoa

307 )

Caguas

821.

Juncos

Piedras

199 "

119 )

Humacao

702 »

Naguabo

334. "

Fajardo

$522 》$

Luquillo

178 )

Loiza

377 ॥

Trujillo

172 ॥

Río Piedras

$213 »$

Cangrejos

Guaynabo

$112 》$

335 »

Bayamón

Toa Baja

$1.370)$

363 ”

584 )

Toa Alta

Corozal

200 »

Vega Alta

129 )

Vega Baja

$161)$

Manatí

885 )

384. »

Utuado

164 .

Camuy

$686 \%$

Arecibo

Total

12.981 vecinos. ${ }^{16}$

16 Ibidem, 9 de junio de 1813. 
En la citada sesión que celebró la Diputación Provincial el 9 de junio de 1813, la misma comisión que elaboró el proyecto de la nueva división de la isla en siete distritos electorales, presentó también un censo de población que representamos en el cuadro número 4.

\section{Cuaro N. 4}

\begin{tabular}{|c|c|c|c|c|c|c|c|}
\hline Parroquias & $\begin{array}{l}N .0 \text { de } \\
\text { almas }\end{array}$ & $\begin{array}{l}N .0 \text { de } \\
\text { vecinos }\end{array}$ & $\begin{array}{c}\text { N.o de } \\
\text { ciudadanos }\end{array}$ & $\begin{array}{c}N .0 \text { de } \\
\text { electores }\end{array}$ & $\begin{array}{l}\text { Corresponder } \\
\text { alcaldes }\end{array}$ & $\begin{array}{l}n \text { Idem } \\
\text { reoidores }\end{array}$ & $\begin{array}{l}\text { Idem } \\
\text { sindicos }\end{array}$ \\
\hline S. Juan & 8.706 & 1.582 & 907 & 17 & 2 & 12 & 2 \\
\hline Vega Alta & 1.531 & 129 & 48 & 9 & 1 & 2 & 1 \\
\hline Vega Baja & 1.381 & 161 & 150 & 9 & 1 & 2 & 1 \\
\hline Corozal & 1.550 & 200 & 85 & 9 & 1 & 4 & 1 \\
\hline Toa Baja & 3.385 & 363 & 85 & 9 & 1 & 4 & 1 \\
\hline Toa Alta & 3.344 & 584 & 273 & 9 & 1 & 6 & 1 \\
\hline Bayamón & 7.431 & 1.370 & 560 & 17 & 2 & 8 & 2 \\
\hline R. Piedras & 2.335 & 213 & 82 & 9 & 1 & 4 & 1 \\
\hline Guaynabo & 2.64 .9 & 335 & 98 & 9 & 1 & 4 & 1 \\
\hline Cangrejos & 808 & 112 & 82 & 9 & 1 & 4 & 1 \\
\hline Trujillo & 2.572 & 172 & 83 & 9 & 1 & 2 & 1 \\
\hline Loiza & 2.916 & 377 & 92 & 9 & 1 & 4 & 1 \\
\hline Luquillo & 1.414 & 178 & 48 & 9 & 1 & 2 & 1 \\
\hline Fajardo & 4.194 & 522 & 352 & 9 & 1 & 6 & 1 \\
\hline Naguabo & 1.916 & 334 & 216 & 9 & 1 & 4 & 1 \\
\hline Humacao & 4.179 & 702 & 352 & 9 & 1 & 6 & 1 \\
\hline Maunabo & 1.233 & 162 & 66 & 9 & 1 & 2 & 1 \\
\hline Barranquitas & 1.309 & 227 & 113 & 9 & 1 & 4 & 1 \\
\hline Piedras & 1.290 & 199 & 5.5 & 9 & 1 & 2 & 1 \\
\hline Juncos & 1.493 & 199 & 133 & 9 & 1 & 2 & 1 \\
\hline Caguas & $6.4: 26$ & 821 & 400 & 9 & 1 & 6 & 1 \\
\hline Hato $G$. & 1.670 & 229 & 104 & 9 & 1 & 1. & 1 \\
\hline S. Germán & 16.523 & 2.208 & 551 & 17 & 2 & 8 & 2 \\
\hline Yauco & 6.004 & 815 & 276 & ) & 1 & 6 & 1 \\
\hline Cabo Rojo & 6.134 & 613 & 325 & り) & 1 & 6 & 1 \\
\hline Mayagüez & 9.634 & 1.402 & 68.5 & 17 & 2 & 8 & 2 \\
\hline
\end{tabular}




\begin{tabular}{|c|c|c|c|c|c|c|c|}
\hline Parroquias & $\begin{array}{l}N . " \text { de } \\
\text { almas }\end{array}$ & $\begin{array}{l}\text { N." de } \\
\text { vecinos }\end{array}$ & $\begin{array}{c}N .0 \text { de } \\
\text { ciudadanos }\end{array}$ & $\begin{array}{l}N .^{\circ} \text { de } \\
\text { electores }\end{array}$ & $\begin{array}{l}\text { Corresponder } \\
\text { alcaldes }\end{array}$ & $\begin{array}{l}\text { Idem } \\
\text { regidores }\end{array}$ & $\begin{array}{l}\text { Idem } \\
\text { síndicos }\end{array}$ \\
\hline Añasco & 7.748 & 1.234 & 64.5 & 17 & 2 & 8 & 2 \\
\hline Coamo & 2.876 & 442 & 210 & 9 & 1 & 4 & 1 \\
\hline Juana 1). & 1.831 & 318 & 129 & 9 & 1 & 4 & 1 \\
\hline Ponce & 9.838 & 1.86 .3 & 712 & 17 & 2 & $\ddot{3}$ & 2 \\
\hline Peñuelas & 3.564 & 564 & 185 & 9 & l & 6 & 1 \\
\hline Cayey & 2.612 & 379 & 88 & 9 & 1 & 4 & 1 \\
\hline Cidra & 1.117 & 143 & 84 & 9 & 1 & 2 & 1 \\
\hline Guayama & 2.519 & 308 & 66 & 9 & 1 & 4 & 1 \\
\hline Patillas & 2.8333 & 360 & 112 & 9 & 1 & 4 & 1 \\
\hline Yabucoa & 2.516 & 907 & 174 & 9 & 1 & 4 & 1 \\
\hline Aguada & 5.395 & 782 & 662 & 9 & 1 & 0 & 1 \\
\hline Aguadilla & 6.196 & 812 & 716 & 9 & 1 & () & 1 \\
\hline Moca & 3.356 & 457 & 449 & 9 & 1 & 1 & 1 \\
\hline Rincón & 3.536 & 565 & 520 & 3 & 1 & 6 & 1 \\
\hline Pepino & 3.877 & 542 & 518 & 9 & 1 & 6 & 1 \\
\hline Arecibo & 6.608 & 686 & 485 & 9 & 1 & 6 & 1 \\
\hline Camuy & 1.013 & 164 & 44 & 9 & 1 & 2 & 1 \\
\hline Utuade & 3.241 & 384 & 305 & 9 & 1 & 1 & 1 \\
\hline Tuna & 3.562 & 422 & 405 & 9 & 1 & 4 & 1 \\
\hline Manati & 6.677 & 885 & 775 & 9 & 1 & 0 & 1 \\
\hline Total & 182.989 & 25.578 & 12.424 & 353 & 51 & 216 & 51 \\
\hline
\end{tabular}

Resumen:

182.989 almas.

$$
\begin{aligned}
& 25.578 \text { vecinos. } \\
& 12.424 \text { ciudadanos. } \\
& 353 \text { electores. } \\
& 51 \text { alcaldes. } \\
& 216 \text { regidores. } \\
& 51 \text { síndicos. }
\end{aligned}
$$

17 Censo de la población de Puerto Rico que la comisión presentó a la Diputación Provincial el 9 de junio de 1813. En él, como vemos, se especifica el número de alcaldes, reqidores y procuradores síndico; que correspondian a cada ayuntamiento de la isla. (A.G.I., Ultramar, 430. Cuaderno núm. 4). 
El cuadro anterior nos muestra que el número de alcaldes, regidores y procuradores síndicos, estaba en función de los vecinos de las localidades. El real decreto de 23 de mayo de 1812, regulaba el artículo 311 de la Constitución, determinando el número de cargos concejiles que habría de corresponder a cada pueblo según unos límites de vecindad que oscilaban entre los 200 y 10.000 vecinos. Para los pueblos de menos de 200 vecinos, los miembros que compondrían su ayuntamiento serían: un alcalde, dos regidores, y un procurador síndico. Para aquellos cuyo número oscilara entre 200 y 500, habría un alcalde, cuatro regidores, y un procurador síndico. Para las poblaciones comprendidas entre 500 y 1.000 , el cabildo estaría formado por un alcalde, seis regidores, y un procurador síndico. Si la población pasaba de los 1.000 vecinos el ayuntamiento lo formarían dos alcaldes, ocho regidores, y dos procuradores síndicos. El real decreto establecía que la capital de la provincia debía tener 12 regidores, alcanzara o no el número de vecinos establecido. Si la capital superaba la cifra de 10.000 , le corresponderían 16 regidores. ${ }^{18}$

En estas circunstancias, en Puerto Rico, las poblaciones que consiguieron dos alcaldes fueron seis: la capital, Ponce, Bayamón, San Germán, Mayagüez y Añasco.

El número total de alcaldes de las primeras elecciones constitucionales, resultó ser 51 . De la renovación de los ayuntamientos a finales de 1813 salieron elegidos 52; el pueblo de Cangrejos que en las primeras elecciones había formado ayuntamiento con Río Piedras, se constituyó en nuevo municipio, eligiendo sus vecinos ciudadanos un alcalde, dos regidores y un síndico respectivamente.

En cuanto al número de electores designado por los ciudadanos para elegir el cabildo, también estaba regulado por el citado decreto. El número de electores o compromisarios variaba entre diecisiete y nueve. Es decir, nueve para las localidades con menos de 1.000 vecinos y diecisiete para aquellas que tuvieran entre 1.000 y 10.000. ¿Quiénes eran estos compromisarios? La lectura de las

18 A.G.I., Ultramar, 426. Real decreto de mayo de 1812. 
actas de la constitución de los ayuntamientos nos lleva a la conclusión, de que, por lo general, los vecinos elegían como sus representantes, a las personas más relevantes de los pueblos. Así es frecuente encontrar entre los electores de la mayoría de las localidades, a los curas párrocos, y a un gran número de oficiales del ejército, tanto en activo como retirados.

\section{Atribuciones de alcaldes $y$ regidores}

Lia Constitución permitió a Puerto Rico la formación de numerosos municipios, a la vez que convirtió a la antigua colonia en una provincia española con una diputación provincial al frente, encargada de promover la prosperidad de la isla. Como dice el profesor Lalinde Abadía, la actitud de España con respecto a los dominios o colonias de América, cambió a partir del año 1808. Desde ese momento, la metrópoli lleva una política de asimilación con sus colonias, intentando igualar los territorios de Ultramar con los de la propia nación española. Este período «asimilista», en su primera fase, se mantiene en Puerto Rico desde 1808 hasta 1823, coincidiendo con las etapas constitucionales que comprenden el bienio y el trienio liberal. ${ }^{19}$

La Constitución doceañista, en su artículo 321, concede a los ayuntamientos una serie de atribuciones de capital importancia para el gobierno de los pueblos. Los cabildos formados por alcaldes, regidores y procuradores síndicos, tenían encomendadas entre otras, las siguientes funciones:

1. Dirigir la policía de salubridad y comodidad.

2. Auxiliar al alcalde en todo lo que pertenezca a la seguridad de las personas y bienes de los vecinos, y a la conservación del orden público.

19 Lalinde Abadía, Jesús: La administración espafiola en el siglo XIX puerto. rriqueño. Sevilla, 1980, págs. 6 a 10. 
3." La administración e inversión de los caudales de propios y arbitrios conforme a las leyes y reglamentos, con el cargo de nombrar depositario, bajo responsabilidad de los que le nombran.

4. Hacer el repartimiento y recaudación de las contribuciones, y remitirlos a las tesorerías respectivas

5. Cuidar de las escuelas de primeras letras, y de los demás establecimientos de educación que se paguen de los fondos del común.

6. Entender en el mantenimiento de los hospitales, hospicios, casa de expósitos y demás establecimientos de beneficencia, bajo las reglas que se prescriban.

7. Llevar a cabo la construcción y reparación de los caminos, calzadas, puentes y cárceles, de los montes y plantíos del común, y de todas las obras públicas de necesidad, utilidad y ornato.

8. Formar las ordenanzas municipales del pueblo, y presentarlas a las Cortes para su aprobación por medio de la Diputación Provincial, que las acompañará con su informe.

9. Promover la agricultura, la industria y el comercio, según la localidad y circunstancias de los pueblos, y cuanto le sea útil y beneficioso. ${ }^{20}$

Todas estas funciones que la Constitución asignaba a los cabildos, se fueron desarrollando y. regulando, en lo posible -no olvidemos el corto espacio de tiempo que estuvo en vigor la Constitución-, a través de decretos dados por las Cortes. A veces el gobernador, juntamente con sus asesores jurídicos, se vio obligado a elaborar ciertas instrucciones que sirvieran para el gobierno de los municipios, mientras llegaban los reglamentos de oficio que debían regir y establecer las atribuciones de las autoridades concejiles.

20 Garófano, R. y Páramo, J. R.: La Constitución..., págs. 86 y 87. 
Atribuciones de los alcaldes

Comenzando con los alcaldes, diremos que la Constitución en su artículo 282, los contemplaba como conciliadores, respecto al poder judicial que les atribuía. Anteriormente habían ejercido la jurisdicción real ordinaria en todo el distrito que les correspondía, otorgando las apelaciones de sus providencias a la Audiencia de Puerto Príncipe, en Cuba, de la que dependía judicialmente todo el territorio puertorriqueño. Bien era cierto que aquellos alcaldes no podían introducirse en materias de gobierno económico, policía y Real Hacienda, para lo cual el gobierno superior de Puerto Rico nombraba cada dos años un juez pedáneo en cada partido, conocido con el nombre de Teniente a guerra.

En lo sucesivo recurrirían a los alcaldes, todos aquellos cue quisieran demandar a otros ante el juez de partido, bien por cuestiones de tipo civil o por injurias. El alcalde se asesoraría de los motivos del litigio a través de dos «hombres buenos», nombrados uno por cada parte.

Enterado del dictamen de los dos asociados, tendría un plazo máximo de 8 días para dar la providencia que le pareciera oportuna con el fin de dar por zanjadas las diferencias. Si las partes litigantes quedaban satisfechas, la sentencia del alcalde se anotaría en un libro dispuesto para este menester. En él firmarían cl alcalde, los dos «hombres buenos» y los interesados.

Los querellantes podían solicitar al alcalde certificaciones del fallo del pleito, el cual debía expedírselas.

Cuando las partes no quedaran satisfechas, también se anotaría en dicho libro, y se facilitarían certificaciones a los litigantes en las que se haría constar que la conciliación no había sido posible.

Los alcaldes podían intervenir, a instancia de parte, en aquellos asuntos que, aunque contenciosos, fuese muy urgente el resolver, y no diese lugar a recurrir al juez de partido, remitiéndoselos posteriormente a éste. 
Todo parece indicar que los alcaldes tuvieron que intervenir en cuestiones de justicia mucho más de lo prevenido. Pensemos que de los siete jueces letrados que correspondían a la isla, según el número de partidos que tenía, sólo se establecieron jueces en dos de ellos. Por otra parte, la anterior afirmación se puede deducir del nombramiento de subalternos que la Diputación hizo para cada ayuntamiento. Así, en sesión celebrada el 21 de mayo de 1813, se acordó que el número de subalternos para los pueblos con un alcalde habría de ser tres: un escribano, un ministro y un alcaide de cárcel. En aquellos pueblos donde residiera el juez letrado, el alcalde debería contar al menos con dos auxiliares: un escribano y un ministro. Consciente la Diputación de la escasez de escribanos o notarios, previene que en los pueblos el oficio de escribano 10 supla el secretario del ayuntamiento.

Funcionamiento de los ayuntamientos durante el bienio constitucional

CFuncionaron los cabildos de la isla, en su corta vida, de acuerdo con el espíritu de la Constitución gaditana? Dos obstáculos difíciles se opusieron a ello: el primero, el poco tiempo que estuvo en vigor la Constitución; gran parte de las medidas adoptadas en estos dos años, fueron tomadas como provisionales hasta que la situación fuera más favorable, ejemplo el nombramiento de los dos únicos jueces letrados; el segundo, la inexistencia política de los españoles de entonces, tanto de los peninsulares, como de los que habitaban en los dominios de América. A este respecto, don Salvador Meléndez Bruna - militar de ideología absolutista- se lamenta en un informe que dirige al secretario de Estado del despacho de la Gobernación de Ultramar, fechado el 2 de enero de 1814, con motivo de haberse renovado los ayuntamientos. En el informe, el gobernador expone que uno de los grandes problemas que se les plantea a los ayuntamientos creados por primera vez, es el carecer de personas letradas que asesoren a sus miembros para que el ca- 
bildo pueda funcionar. Según el propio gobernador, el citado problema se resolvía, en el mejor de los casos, recurriendo los alcaldes al gobierno superior para que les aclarasen hasta las más nimias tareas que debían ejecutar. Pero a veces, incluso así, el asesoramiento del gobierno a los miembros de algunos municipios resultaba vano, ya que se trataba de hombres que apenas sabían leer y escribir.

Otra de las cuestiones que el gobernador expone a las autoridades de la península, es la de haber tenido que poner reparos a la elección de alcaldes recaída en ciertos secretarios de ayuntamientos. De igual modo tuvo que hacer lo mismo con los oficiales de milicias que servían en las planas mayores y tenían sueldos como veteranos. Todo esto, fue sin duda alguna, el reflejo de la situación de los habitantes de la isla, y de la excesiva tutela política que la metrópoli había tenido con ellos hasta aquel momento. ${ }^{21}$

LOS AYUNTAMIENTOS PUERTORRIQUEÑOS

DURANTE EL TRIENIO CONSTITUCIONAL

Es más que conocido que el regreso a España a principios de 1814 de Fernando VII, trajo consigo la derogación de la Constitución liberal elaborada por las Cortes de Cádiz.

El rumbo político que volvía a tomar la metrópoli, llevaba aparejado la abolición del régimen constitucional y por lo tanto la supresión de los ayuntamientos surgidos en 1812 .

No obstante, la estructura municipal puertorriqueña creada al amparo de la Constitución, en cuanto a la existencia de un municipio en casi todas las localidades de la isla, permaneció intacta. Es decir, esos cabildos dejaron de ser órganos representativos de los vecinos ciudadanos, pero no desaparecieron como tales. Es más, durante el llamado sexenio absolutista el número de ayuntamientos en Puerto Rico creció de 45 a 49.

21 A.G.I., Ultramar, 4¿6. 12 de enero de 1814. 


\section{El municipio en el periodo absolutista}

Del funcionamiento de estos municipios nos habla Pedro Tomás de Córdova, por entonces oficial mayor de la Secretaría del Gobierno y Capitanía General de la isla, en un informe que dirige al rey en espera de conseguir algunas reformas locales, el 28 de octubre de 1818. Después de confirmar que los alcaldes de las villas eran elegidos por los ayuntamientos de éstas, con arreglo a las Leyes de Indias, y que los de los pueblos eran nombrados por el gobernador y el intendente, don Pedro Tomás de Córdova, propone al monarca la necesidad de crear en Puerto Rico tres villas más, que con las cuatro ya existentes y la capital, fueran cabezas de los ocho partidos en que según él, sería conveniente dividir a la isla. ${ }^{22}$ Para su entender, en cada pueblo, debería nombrarse por el gobierno un alcalde pedáneo, y en las villas, un teniente de justicia mayor que tuviera jurisdicción ordinaria, designado también por la primera autoridad. A aquél, le correspondería presidir el ayuntamiento, y ser el conducto con quien la autoridad superior de la isla se entendiera en los asuntos políticos y de justicia. También hace constar la necesidad de establecer un escribano público en cada villa. ${ }^{23}$

Las razones en que Tomás de Córdova basaba la reestructuración de la administración local puertorriqueña, estaban fundamentadas en la experiencia. En general, durante los nueve meses que habían ejercido los seis tenientes de justicia mayor, establecidos en cumplimiento de la real cédula de gracias de 1815, el aumento y el progreso de las poblaciones había sido un hecho.

Es posible que el proyecto que proponía el oficial mayor del Gobierno y Capitanía General hubiese resultado operante, pero el régimen absolutista radical impuesto en España tras el regreso del rey, se iba deteriorando, por lo que después de los consabidos

22 La tradición de conceder el título de villa a ciertas localidades fue algo característico de los monarcas españoles. Esta tradición se extendió a los dominios de España en América. El título de villa entrañaba ciertos privilegios para la localidad. La villa constituía un núcleo de población intermedio entre pueblo y ciudad.

23 A.G.l., Ultramar, 434, cuaderno, núm. 4. 
pronunciamientos militares, Fernando VII, se vio obligado a jurar la Constitución.

\section{Los ayuntamientos del tricnio liberal}

Recibidas las primeras noticias del establecimiento, por segunda vez, del régimen liberal, el nuevo gobernador de Puerto Rico, Juan Vasco Pascual se apresuró a divulgar un comunicado en el que se declaraba vigente la Constitución de 1812. Un mes después, es decir, en junio de 1820 , se llevarían a cabo las elecciones municipales, que dotarían de nuevo a los cabildos de la isla de alcaldes constitucionales. ${ }^{24}$

Elegidos los ayuntamientos, según la normativa indicada ya en el bienio liberal, éstos fueron recibiendo las instrucciones correspondientes de acuerdo con el espíritu de la Constitución.

Si nos ceñimos al terreno de la enseñanza o al de los derechos de la persona, nos encontramos con que el nuevo gobernador de la isla, Gonzalo Aróstegui Herrcra, envió una circular a cada municipio, cuando apenas había tomado posesión de su cargo, proponiendo el establecimiento de escuelas según el método de enseñanza de Lancaster. ${ }^{25}$ En la misma, dada el 16 de agosto de 1820, proponía igualmente el establecimiento de una cátedra de Constitución.

En sesión celebrada el 20 de agosto de 1820, la Diputación Provincial acordó solicitar al gobernador que enviara un oficio al obispo, superiores de los conventos y a todos los ayuntamientos de la isla, instándoles a que guardaran y cumplieran el decreto de 8 de septiembre de 1813 por el cual se abolía la pena de azotes.

24 Cruz Monclova, Lidio: Historia de Puerto Rico. (Siglo XIX). Puerto Rico, 1958, tomo I, págs. 141 a 146.

$25 \mathrm{El}$ método de ensef́anza Lancaster que propuso el gobernador Aróstegui para los niños puertorriqueños es conocido en pedagogía como el modo mutuo. Consiste en la colaboración de los alumnos más aventajados en la enseñanza colectiva, por lo cual los escolares se instruyen mutuamente. Aunque se trata de un método utilizado ya en la antiguledad, fue difundido, especialmente en los países de habla inglesa, por Bell y Lancaster. Presenta la ventaja de que se puede instruir a un gran número de alumnos con pocos maestros. (Vid. Titone, Renzo: Metodología Didattica. Roma, 1962). 
El móvil que impulsaba a la Diputación a pedir al jefe superior que tomara tal resolución, se fundaba en las noticias que tenía de que aún se practicaba en las clases la latinidad de San Ildefonso, en las de los dos conventos, y en algunas de las escuelas, la antigua corrección del azote. ${ }^{26}$

Por su parte, los ayuntamientos, a medida que recibían las instrucciones pertinentes, comenzaban a realizar las funciones que les encomendaba la Constitución.

Sabemos que el ayuntamiento de Peñuelas, por acta remitida al gobernador, se reunió en sesión ordinaria el 4 de septiembre de 1820. En dicha reunión se acordó lo siguiente:

"Que las reses y bestias sueltas que hacen daño a las labores del vecindario se lleven a la cárcel, exigiéndoles a sus dueños un peso por cada cabeza con aplicación al fondo de propios. Y que los cerdos y ganado lanar que se encuentren haciendo daño en los scmbrados - continuaba más adelante--, se maten y se entreguen al regidor de policías, quien hará expender su carne y sacará de su producto un peso por cabeza aplicándose al mismo fondo, y con el resto se pagará el daño que cause, y si sobrare se repartirá a los presos y pobres, multando con cuatro pesos a todo el que impidiere la conducción al pueblo de dichos animales que también se aplica. rán al fondo de propios».. ${ }^{27}$

En sesión celebrada por la Diputación Provincial el 30 de septiembre de 1820, se acordó aprobar los acuerdos adoptados por el ayuntamiento de Peñuelas, con la salvedad de que la carne de los animales sacrificados, cultivadas, se entregarán en su totalidad a sus dueños, sin excluir a éstos de pagar los daños que dichos animales hubieran causado a las siembras de los vecinos.

Si el asunto tratado por el ayuntamiento de Peñuelas es típicamente rural, y las soluciones que la propia corporación adopta

26 «Gaceta del Gobierno Constitucional de Puerto Rico», 1821, núm. 5.

27 Ibídem, número 8. 
indican claramente reminiscencias del pasado, no ocurre lo mismo con la actitud del ayuntamiento de Guaynabo, al tratar de resolver un problema más bien propio de nuestros días: la especulación del suelo en las zonas adecuadas para la construcción de viviendas. En efecto, en el acta enviada al gobernador se plantean las dificultades que tienen los vecinos de esta localidad para construir sus casas. En la reunión que mantuvo el cabildo de dicho pueblo el 18 de septiembre de 1820 , se acordó solicitar al jefe superior que obligara al dueño de los terrenos que circundaban la parroquia, a vender éstos «a justa tasación» para que los vecinos que quisieran construir pudieran hacerlo. Según el citado ayuntamiento, aunque habían transcurrido 40 años desde que se erigió la parroquia, los vecinos aún no podían construir sus casas. Los motivos que habían ocasionado tal demora eran bien claros: el precio abusivo de los solares; un peso por vara.

Después de debatir el tema, la Diputación acordó juntamente con el gobernador, solicitar un informe al dueño de los terrenos para poder obrar adecuadamente. Una de las cuestiones que suscitaron desacuerdos entre el gobernador y el intendente - por entonces don Luis de Santiago- fue la expedición de títulos a los agraciados en el repartimiento de tierras realengas, y baldíos. La querella, llevada a la Diputación fue ganada por el gobernador a quien el órgano representativo máximo de la provincia -artículo 325 de la Constitución - atribuyó el derecho a despachar dichos títulos. El argumento esgrimido por la Diputación, se basó en los decretos de Cortes de 4 de enero de 1813 y 8 de junio del mismo año, que atribuían a los ayuntamientos y diputaciones provinciales las facultades de distribuir los terrenos de baldíos, realengos, y de propios. Por tanto, era al gobernador de la provincia al que correspondía tal prerrogativa, por ser el presidente de la Diputación. ${ }^{28}$

Entre los graves problemas que afectaban a Puerto Rico en el primer cuarto del siglo XIX figuraba la delincuencia. Así lo manifestaba Pedro Tomás de Córdova en el informe de la isla que presentó a Fernando VII en 1818:

28 Ibídem, nủmero 9. 
"La falta de un Tribunal Superior en la isla — decía Tomás de Córdova- es tan notable, como que por su inexistencia quedan los delitos impunes, ya por la distancia que hay a la Audiencia Territorial, ya porque esta misma causa proporciona que no se haga todo el caso debido por los subalternos para desterrar un mal tan nocivo en la sociedad, y ya porque en el concepto de evitarse éste, se destinan los delincuentes al presidio correccional por un tiempo muy limitado, medida insuficiente para contener a los malévolos). ${ }^{29}$

Por eso, en real orden de 11 de septiembre de 1820, comunicada al gobernador, se arbitraban los medios para combatir dicho mal. La real orden va dirigida a los jefes políticos, a los alcaldes y a los ayuntamientos constitucionales. A éstos se les previene de la obligación que tienen de velar muy eficazmente, bajo su responsabilidad, por aquellos que no tienen empleos, oficios o modo de vivir conocido. Dicha orden, consta de cuatro artículos y se remite en su apartado 2. a la real orden de 30 de abril de 1745, y al real decreto de 7 de mayo de 1775, Ley 7, título 31, libro 12 de la Novísima Recopilación. Todas las personas anteriormente citadas, incluyendo también a los gitanos — según la legislación al respecto- habían de ser perseguidos y encarcelados tras la información que justificara su mal comportamiento. La citada orden contempla la obligación de enviar a los delincuentes a las casas de misericordia, hospicios, arsenales o a cualquier establecimiento donde trabajen y no sean «gravosos para el Estado». Las penas impuestas a tales individuos no podrían pasar de dos años, aunque los jueces podían rebajarlas a menos tiempo. Las personas tipificadas como maleantes podían cumplir condena trabajando en las obras públicas de sus pueblos o de los más inmediatos; pero las sanciones impuestas se someterían a la determinación de la Audiencia Territorial. ${ }^{30}$

Una de las características de la etapa colonial, señalada por los historiadores, fue la de celebrar con grandes solemnidades cualquier acontecimiento singular ocurrido bien en la metrópoli o en la co-

29 A.G.I., Ultramar, 434, cuaderno núm. 6.

30 \&Gaceta del Gobierno Constitucional de Puerto Rico», 1821, núm. 10. 
lonia. Esta idiosincrasia, manifestada por los puertorriqueños todavía en el siglo pasado, les llevaba a festejar, con igual entusiasmo, la caída o subida de las fuerzas políticas que alternaban el poder en la España decimonónica.

Durante el trienio liberal los festejos llegaban al máximo cuando se trataba de celebrar algún acontecimiento de carácter político, desde la elección del diputado a Cortes, hasta la simple colocación de una lápida constitucional en la plaza de alguna localidad de la isla. Sirva como ejemplo, la descripción que don Joaquín Goyena, alcalde de Guaynabo nos hace de las fiestas celebradas en honor de la Constitución al colocar una lápida conmemorativa en la fachada del ayuntamiento.

En oficio dirigido a don Gonzalo Aróstegui, el 14 de junio de 1821, el alcalde constitucional de Guaynabo relata paso a paso el programa de festejos que el ayuntamiento organizó con motivo de la ya citada efeméride. Los días señalados para festejar tal acontecimiento fueron el 9 y 10 del mes en cuestión, celebrándose carreras de caballos, ceremonias religiosas, discursos políticos, desfiles procesionales exhibiendo la lápida, y recepción costeada por el párroco del pueblo, don Joaquín Ramón Rodríguez, algunos vecinos y el alcalde. Por supuesto, el ejemplo de Guaynabo no fue un caso aislado ni mucho menos; Manatí, pueblo por entonces de unos 368 ciudadanos, y una población total que doblaba a la de Guaynabo, hizo también lo mismo. Igualmente otras localidades de la provincia, colocaron lápidas constitucionales en las fachadas de sus ayuntamientos o edificios importantes de la plaza principal, con el consiguiente entusiasmo y regocijo de los vecinos. ${ }^{31}$

31 Ibídem, número 54 . Es evidente que el gobierno colonial impulsaba a los puertorriqueños a festejar cualquier evento político independientemente de la ideología que profesara el partido que ejercía el poder en la metrópoli. Esta aseveración se puede comprobar en la evolución de política de la isla a lo largo del siglo XIX, y especialmente durante el periodo que nos atane. Sin embargo, esta manera peculiar de introducirse en los distintos cambios políticos, parece que trasciende hasta el siglo XX. En efecto, en julio de 1952, los puertorriqueños inauguraron con grandes solemnidades la «Constitución del Estado Libre Asociado de Puerto Rico», que el Congreso de los Estados Unidos había confirmado el 3 de julio del mismo año. 


\section{El Reglamento Municipal de 1822}

Nunca, como durante el trienio liberal, se había intentado reglamentar y uniformar el funcionamiento de todos los ayuntamientos de Puerto Rico. Para ello, las autoridades superiores editaron un reglamento económico que sirviera de modelo a los municipios de toda la isla. El reglamento, imprimido en los talleres del gobierno, salió a la luz en el año 1822. Aquel conjunto de disposiciones encomendadas al buen gobierno de los ayuntamientos, constaba de 34 artículos que pueden agruparse en dos apartados: el funcionamiento interno del cabildo, y el de las obligaciones del secretario.

En cuanto a las obligaciones de la corporación comienza fijando las sesiones ordinarias de ésta, que han de ser por lo menos cuatro cada mes del año, y concretamente el miércoles de cada semana. Si las circunstancias lo exigían la corporación podía reunirse de manera extraordinaria en cualquier momento. La ausencia de alguno de sus componentes estaba penalizada con la multa de dos pesos, a no ser que estuviera justificada por encontrarse impedido el individuo en cuestión. Las normas contenidas en dicho reglamento, llegaban incluso a determinar la hora de comienzo de las sesiones: las diez de la mañana. Una vez empezada la reunión, se procedía a la lectura del acta anterior por parte del secretario, signándose ésta inmediatamente por parte de los regidores que la autorizaban.

Firmada el acta se pasaba a las lecturas de la «Gaceta del Gobierno Constitucional de Puerto Rico», así como de las circulares y oficios enviados por el gobierno.

La suscripción a la «Gaceta» fue algo obligatorio a los ayuntamientos, ya que se trataba de una publicación en la que aparecían todas las leyes, decretos y comunicados dados por el gobierno superior de la isla.

Acto seguido, se tomarían los acuerdos pertinentes, pasándose a nombrar las comisiones especiales que se encargarían de resolver las cuestiones planteadas en los informes y oficios recibidos. Los informes enviados por otras autoridades, así como los presentados 
por los regidores se estudiaban después, examinándose si las proposiciones de éstos eran competencia del ayuntamiento o no.

En el caso en que lo planteado se saliera del círculo de atribuciones que tenían encomendadas los ayuntamientos, los informes se remitían a la autoridad competente, absteniéndose éstos de tomar cualquier actitud. Llegado este momento de la sesión, el alcalde presidente invitaba a todos los miembros de la corporación a que propusieran libremente todo aquello que redundara en el bienestar de los vecinos; haciéndose constar en el acta y asentándose también separadamente en un libro destinado al efecto, que debía existir en cada ayuntamiento, la proposición hecha y el nombre del individuo que la hizo.

Estas proposiciones podían presentarse por escrito o bien verbalmente, determinando la reunión si eran admisibles o no. Si las propuestas eran asumidas por la corporación, se sometían a dos discusiones antes de proceder a la votación. También correspondía al conjunto de la corporación el observar si las propuestas eran de carácter urgente o podían ser estudiadas en la sesión siguiente.

La mayoría de votos era la que decidía ante cualquier acuerdo que se tomara. Las opiniones sobre los asuntos tratados podían emitirse por aclamación o de manera secreta, si algún miembro lo pedía. El resultado, en el que la mayoría simple era suficiente, se reflejaba en el acta que se remitía mensualmente al gobierno político de la provincia.

Después de discutidas las proposiciones y tomados los acuerdos, tocaba el turno al regidor de policía. Este entraría por semana, alternándose todos los componentes de la corporación. Durante su turno bajo ningún pretexto podía abandonar el pueblo, sin el consentimiento del alcalde. El regidor de policía tenía la obligación de dar cuenta de todo lo que ocurría durante la semana. El reglamento señalaba bien la obligación y responsabilidad del citado regidor de no omitir nada. Su misión era la de contribuir al sostenimiento del orden público.

A continuación del regidor de policía debían dar cuenta de 
sus comisiones los regidores de recaudación de subsidios, gastos públicos y fondos de propios y arbitrios.

Uno de los puntos en que más insiste el reglamento municipal de 1822, es el referente al comportamiento de los capitulares durante las sesiones de trabajo. En él se prohibía tasativamente fumar, conversar o distraerse en otras cosas. Ninguno de los regidores podía tomar la palabra sobre el mismo asunto más de dos veces. En el artículos 23 del reglamento se especifica que ningún capitular «podrá dejar su puesto sin expreso permiso del alcalde presidente». En caso de no guardar los requisitos exigidos, era el presidente de la corporación el que reprendía al individuo incurioso, siendo el síndico el encargado de recordar a éste, el deber de cumplir las normas establecidas. Por último, en lo que a la disciplina se refiere, el alcalde presidente podía imponer una sanción de uno o dos pesos a aquel o aquellos que después de llamados al orden por primera vez, continuasen infringiendo algún artículo del reglamento.

El otro apartado en que hemos dividido al reglamento hace alusión a las obligaciones del secretario del ayuntamiento. La figura de éste se contempla en el artículo 320 de la Constitución. Elegido a pluralidad de votos por la corporación, no tenía obligatoriamente que ser escribano, según el decreto de 10 de julio de 1812. Además no podía ser cesado de su cargo sin que lo autorizara la Diputación Provincial. Las funciones que le encomendaban las instrucciones del reglamento económico eran las siguientes:

Tenía que formar expedientes de todos los asuntos que no se decidían en una sola sesión; era el encargado de remitir todos los meses al gobierno político superior, una copia certificada de las cuatro actas de las sesiones celebradas por el ayuntamiento, procurando no remitirlas en pliegos separados; debía llevar la correspondencia del cabildo; tenía a su cargo la formación de las estadísticas y repartimiento del partido, según las normas dadas por la corporación - artículo 30 del reglamento-; también correspondía al secretario cuidar del archivo del municipio, agrupando los documentos por orden de negociados y años; además era de su obli- 
gación controlar el libro de matrícula de extranjeros domiciliados en el distrito o partido, así como el libro de ordenanzas municipales, una vez que éste hubiera sido sancionado por la corporación.

Por último, diremos que el reglamento se podía leer en un pleno, al menos una vez al mes, y dar cuenta de ello al gobierno superior en el pliego que se le enviaba, para dar prueba de su fiel observancia. ${ }^{32}$

La renovación de alcaldes, regidores y sindicos

Según el artículo 313 de la Constitución, «todos los años en el mes de diciembre se reunirán los ciudadanos de cada pueblo, para elegir a pluralidad de votos, con proporción a su vecindario, determinado número de electores que residan en el mismo pueblo $y$ estén en el ejercicio de los derechos de ciudadanos». ${ }^{33}$

Siguiendo fielmente el mandato constitucional, el 11 de noviembre de 1822, el nuevo gobernador de Puerto Rico, don Francisco González Linares expidió una circular dirigida a todos los ayuntamientos, con el fin de renovar los alcaldes, regidores y síndicos para el año 1823:

"Siendo de la mayor importancia el que las elecciones de indivi. duos para la renovación de ayuntamientos, se haga con toda solem. nidad, aciertos y cumplimiento de las leyes -decía don Francisco González Linares-, resuelto expedir la presente circular, para que sirviendo de regla general, lleve este importante asunto la marcha majestuosa que le pertenece, y el sello legal que por sí requiere, evitando con escrupuloso cuidado, los retardos y recla-

32 A.G.I., Ultramar, 425. De la importancia de los secretarios de ayuntamiento nos habla Concepción de Castro en su obra: La Revolución Liberal y los municipios españoles. Asimismo la autora plantea la polémica surgida por parte de algunos ayuntamientos con respecto a si el cargo debia ser vitalicio o renovable cada año. Vid. Castro, Concepción de: La Revolución Liberal y los municipios espanioles. Madrid, 1979, págs. 81 y 82.

33 Garófano, R. y Páramo, J. R.: La Constitución..., pág. 85. 
maciones que necesariamente resultan de no cumplirse estrictamente con lo prevenido para estos actos).. ${ }^{34}$

La circular prevenía el nombramiento de electores para el domingo día 8 de diciembre, y la elección de los cargos concejiles para el siguiente domingo del mismo mes, es decir, para el día 15 . El procedimiento a seguir tanto para el nombramiento de electores, como para la elección de los capitulares estaba regulado por los decretos de 23 de mayo de 1812 y 23 de junio de 1813. Para ambos casos los vecinos con derechos ciudadanos reunidos en junta, presidida por el alcalde y el párroco del pueblo, nombrarían previamente dos escrutadores y un secretario, según real orden de 16 de noviembre de 1821 . Antes de proceder al nombramiento de electores el presidente de la junta electoral tenía la obligación de preguntar si algún ciudadano de los presentes estaba coaccionado para emitir su voto a una determinada persona. En caso afirmativo el aludido debería hacer justificación pública y verbal allí presente. Si la acusación era cierta, los implicados eran privados de voz activa y pasiva. Esta decisión de la junta era irrevocable, es decir, no se podían poner recursos contra ella; no obstante, sólo tenía validez para aquellas elecciones.

Después de haberse llevado a cabo las formalidades anteriores se procedía a la votación de electores. Cada ciudadano proponía un número de personas igual al número de electores que correspondía a la población. Nadie podía votarse a sí mismo bajo pena de perder su derecho al voto.

Acercándose a la mesa formada por el alcalde, escrutadores y secretario, el ciudadano designaba a quienes creía más idóneos para tal fin, escribiendo el secretario en una lista, en su presencia, el nombre de quien votaba, y aquellos por quienes votaba. ${ }^{35}$

Terminada la votación, y efectuado el recuento, el presidente de la mesa, leía en voz alta los nombres de los ciudadanos elegidos,

34 A.G.I., Ultramar, 425.

35 Ibidem. 
extendiéndose un acta a cada uno de éstos para hacer constar su nombramiento.

Finalizado el proceso electoral la junta se disolvía, trasladándose a la parroquia los ciudadanos que la habían constituido, donde se cantaba un solemne tedéum.

$\mathrm{Al}$ siguiente día festivo, en este caso concreto era el domingo 15 de diciembre, se formaría la junta de electores, siguiéndose el mismo procedimiento practicado el domingo anterior. Tal y como establecía el artículo 55 de la Constitución, ninguno de los elegidos podía excusarse de este encargo por motivo ni pretexto alguno, ni presentarse con armas en la junta. Cada elector debía presentar en la mesa la certificación de su nombramiento. Concluidos los detalles previos, los electores y el presidente de la junta -el alcalde o en su defecto el regidor más antiguo- pasaban a la iglesia para oír misa, oficiada por el eclesiástico de mayor dignidad que hubiera en la villa o pueblo. A continuación de este acto, los electores se trasladaban a la casa consistorial donde se realizaba el sufragio de los cargos que debían renovarse en el ayuntamiento.

Terminada la votación, el presidente, escrutadores, y secretario efectuaban el recuento de votos, y hacían públicos los resultados.

Los elegidos deberían tomar posesión de sus cargos el día primero de enero de 1823. Los electores debían tener presente que los individuos elegidos para un determinado cargo en el ayuntamiento, alcalde, regidor, o síndico, no podían desempeñar otro en la misma corporación, al menos durante el tiempo que durara el nombramiento - según el artículo 313 de la Constitución.

En el cuadro n. ${ }^{\circ} 5$ se expresa el número de alcaldes, regidores y procuradores síndicos que había que renovar en Puerto Rico para el año 1823; asimismo se refleja en éste la diferencia existente entre vecinos y electores. Como puede verse el número de alcaldes, procuradores síndicos y regidores estaba en función del de vecinos como ya hemos indicado, en las páginas anteriores. Igualmente los electores o compromisarios que elegían los vecinos ciudadanos, también dependían del número total de vecinos de su población. 
Cuadro n.・5

Iyuntamientos

Corresponden

Hay que renovar

N." de N.o de N." de N." de N.n de N.o de N.o de N.o de

vecinos electores alcaldes regids. sindicos alcaldes regidores sindicos

\begin{tabular}{|c|c|c|c|c|c|c|c|}
\hline Capital & 854 & 15 & 2 & 12 & 2 & 2 & 6 \\
\hline Aguada & 754 & 9 & 2 & 6 & 1 & 2 & 3 \\
\hline Aguadilla & 1.174 & 15 & 2 & 8 & 2 & 2 & 4 \\
\hline Añasco & 1.101 & 15 & 2 & 8 & 2 & 2 & 4 \\
\hline 4recibo & 1.471 & 15 & 2 & 8 & 2 & 2 & 4 \\
\hline Barranquitas & 318 & 9 & 1 & 4 & 1 & 1 & 2 \\
\hline Bayamón & 1.411 & 15 & 2 & 8 & 2 & 2 & 4 \\
\hline Cabo Rojo & 1.528 & 15 & 2 & 8 & 2 & 2 & 4 \\
\hline Caguas & 1.604 & 15 & 2 & 8 & 2 & 2 & 4 \\
\hline Cayey & 532 & 9 & 2 & 6 & 1 & 2 & 3 \\
\hline Camuy & 567 & 9 & 2 & 6 & 1 & 2 & 3 \\
\hline Cidra & 353 & 9 & 1 & 4 & 1 & 1 & 2 \\
\hline Coamo & 906 & 9 & 2 & 6 & 1 & 2 & 3 \\
\hline Corozal & 456 & 9 & 1 & 4 & 1 & 1 & 2 \\
\hline Fajardo & 817 & 9 & 2 & 6 & 1 & 2 & 3 \\
\hline Guayama & 495 & 9 & 1 & 4 & 1 & 1 & 2 \\
\hline Guaynabo & 521 & 9 & 2 & 6 & 1 & 2 & 3 \\
\hline Gurabo & 279 & 9 & 1 & 4 & 1 & 1 & 2 \\
\hline Hato Grande & 4.09 & 9 & 1 & 4 & 1 & 1 & 2 \\
\hline Humacao & 764 & 9 & 2 & 6 & 1 & 2 & 3 \\
\hline Juana Diaz & 403 & 9 & 1 & 4 & 1 & 1 & 2 \\
\hline Juncos & 342 & 9 & 1 & 4 & 1 & 1 & 2 \\
\hline Loiza & 539 & 9 & 2 & 6 & 1 & 2 & 3 \\
\hline Luquillo & 210 & 9 & 1 & 4 & 1 & 1 & 2 \\
\hline Lacy & 191 & 9 & 1 & 2 & 1 & 1 & 1 \\
\hline Mayagủez & 2.567 & 15 & 2 & 8 & 2 & 2 & 4 \\
\hline Manati & 512 & 9 & 2 & 6 & 1 & 2 & 3 \\
\hline Moravis & 24.5 & 9 & 1 & 4 & 1 & 1 & 2 \\
\hline Maunabo & 262 & 9 & 1 & 4 & 1 & 1 & 2 \\
\hline Moca & 755 & 9 & 2 & 6 & 1 & 2 & 3 \\
\hline Naguabo & 389 & 9 & 1 & 4 & 1 & 1 & 2 \\
\hline
\end{tabular}

I'omo XLVII 
Ayuntamientos

\begin{tabular}{lcc}
\multicolumn{4}{c}{ Corresponden } \\
$N . "$ de & $N .0$ de $N .{ }^{\circ}$ de & $N . "$ de \\
vecinos & electores alcaldes & regids.
\end{tabular}

Hay que renovar vecinos electores alcaldes regids.

sindicos alcaldes regidores sindicos

\begin{tabular}{|c|c|c|c|c|c|c|c|c|}
\hline Patillas & 534 & 9 & 2 & 6 & 1 & 2 & 3 & 1 \\
\hline Peñuelas & 934 & 9 & 2 & 6 & 1 & 2 & 3 & 1 \\
\hline Pepino & 1.026 & 15 & 2 & 8 & 2 & 2 & 4 & 1 \\
\hline Pjedras & 358 & 9 & 1 & 4 & 1 & 1 & 2 & 1 \\
\hline Porlier & 250 & 9 & 1 & 4 & 1 & 1 & 2 & 1 \\
\hline Ponce & 2.038 & 15 & 2 & 8 & 2 & 2 & 4 & 1 \\
\hline Rincón & 406 & 9 & 1 & 4 & 1 & 1 & 2 & 1 \\
\hline Rio P. y & 412 & 9 & 2 & 6 & 1 & 2 & 3 & 1 \\
\hline Cangrejos & 132 & & & & & & & \\
\hline S. Germán & 3.284 & 15 & 2 & 8 & 2 & 2 & 4 & 1 \\
\hline Sabana Grande & 387 & 9 & 1 & 4 & 1 & 1 & 2 & 1 \\
\hline Toa Alta & 689 & 9 & 2 & 6 & 1 & 2 & 3 & 1 \\
\hline Toa Baja & 479 & 9 & 1 & 4 & 1 & 1 & 2 & 1 \\
\hline Trujillo & * & - & 1 & 4 & 1 & 1 & 2 & 1 \\
\hline Vega Alta & 160 & 9 & 1 & 4 & 1 & 1 & 1 & 1 \\
\hline Vega Baja & 385 & 9 & 1 & 4 & 1 & 1 & 2 & 1 \\
\hline Utuado y & 501 & 9 & 2 & 6 & 1 & 2 & 3 & 1 \\
\hline Adjuntas & 120 & & & & & & & \\
\hline Yabucoa & 643 & 9 & 2 & 6 & 1 & 2 & 3 & 1 \\
\hline Yauco & 1.046 & 15 & 2 & 8 & 2 & 2 & 4 & 1 \\
\hline Isabela & 1.087 & 15 & 2 & 8 & 2 & 2 & 4 & 1 \\
\hline
\end{tabular}

Fin del trienio liberal

Es evidente que en España el último período liberal del primer cuarto del siglo XIX, estuvo presidido por el fantasma de la subversión, al igual que lo estuviera el sexenio absolutista que le precedió. En los primeros meses de 1823, el trienio liberal entraba en su última fase al penetrar en territorio español los 100.000 hijos de San Luis al mando del duque de Angulema. El objetivo del ejér-

36 Ibídem.

- El Ayuntamiento de Trujillo no remitió el censo de 1822 al gobierno, por lo tanto renovó el mismo número de cargos concejiles que en las elecciones anteriores.

Anuario de Éstudios Americanos 
cito extranjero era devolver a Fernando VII el poder absoluto perdido en 1820.

No obstante, los puertorriqueños liberales parecían ajenos a los acontecimientos de la península y celebraron, como de costumbre, la elección del diputado a Cortes, recaída en don Ildefonso Sepúlveda.

Cuando en la isla se tuvieron noticias de la invasión de España por el ejército de la Santa Alianza, las corporaciones y los funcionarios se apresuraron a realizar todo tipo de protestas contra aquella situación, y a manifestar su adhesión al régimen liberal.

De momento los dos gobernadores insulares: don Francisco González de Linares, gobernador civil, y don Miguel de la Torre, gobernador militar, se sumaron al sentir de los liberales. Posteriormente la trayectoria de cada uno siguió rumbos distintos: González de Linares cuando tuvo noticias de la caída del régimen constitucional se adelantó a renunciar a su cargo sin haber recibido ninguna comunicación oficial que se lo indicara; de la Torre, por su parte, también se adelantó a los acontecimientos, apenas enterado de la caída de los liberales por el gobernador de la Martinica, abolió el rgimen constitucional en Puerto Rico. Su actitud le valió el reconocimiento de los absolutistas, quienes lo confirmaron en su cargo hasta la llegada al poder de otro gobierno constitucional. ${ }^{37}$

La restauración del absolutismo acabó con los ayuntamientos constitucionales, tanto del territorio peninsular, como de sus islas y posesiones ultramarinas.

El Puerto Rico, el nuevo régimen ordenó la reorganización de los antiguos ayuntamientos. Por su parte, don Miguel de la Torre, ahora al servicio de la ideología absolutista, restringió las libertades personales de los puertorriqueños hasta el extremo de prohibir las reuniones nocturnas. De igual modo, prohibió el que se hablara de la Constitución, así como el que los vecinos transitaran por las calles de las poblaciones, después de las diez de la noche. ${ }^{38}$

\section{Antonio Gómez Vizuete}

37 Figueroa, L.: Breve Historia..., pág. 51.

38 Toro Bayron, Fernando: Elecciones y Partidos Politicos en Puerto Rico (1809-1976). Mayagüez, 1977, pág. 36. 